\title{
Climate precursors of multidecadal drought variability in the western United States
}

\author{
Hugo G. Hidalgo \\ Climate Research Division, Scripps Institution of Oceanography, University of California, San Diego, La Jolla, California, \\ USA
}

Received 19 May 2004; revised 16 July 2004; accepted 13 September 2004; published 7 December 2004.

[1] Low-frequency (periodicities lower than 20 years) hydrologic variability in the western United States over the past 500 years is studied using available tree-ring reconstructions of Palmer Drought Severity Index (PDSI), streamflow, and climate indices. Leading rotated principal component (RPC) scores of a gridded tree-ring reconstruction of the PDSI from 1525 to 1975 are significantly correlated with indices representing large-scale climate variations from the Pacific and Atlantic Oceans. RPC1 $(31 \%)$ is related to the influence of North Pacific sea surface temperature (SST) variations, indexed by the Pacific Decadal Oscillation (PDO). RPC2 (24\%) is apparently related to North Atlantic SST variations, indexed by the Atlantic Multidecadal Oscillation (AMO). RPC3 (19\%) is moderately correlated with a smoothed version of the Southern Oscillation Index. Consistent with recent studies of instrumental data, RPC1 (PDO) and RPC2 (AMO) explain a large part of the multidecadal hydrologic variability of the interior western United States. Western U.S. PDSI variability exhibits significant pentadecadal (and longer) oscillations in the epochs from circa 1525 to 1650 and 1850 to 1975, while bidecadal oscillations are prevalent in the middle epoch from circa 1650 to 1850. The changes in spectral characteristics of western U.S. PDSI were related to similar changes in the PDO (and therefore in RPC1). In contrast, RPC2 had a regular periodicity of 51 years for the past $\sim 500$ years. This regularity is intriguing, and although RPC2 was primarily related to the AMO in this study, the influence from Pacific climate cannot be discarded. INDEX TERMS: 1812 Hydrology: Drought; 1833 Hydrology: Hydroclimatology; 1854 Hydrology: Precipitation (3354); 1860 Hydrology: Runoff and streamflow; KEYWORDS: AMO, drought, low frequency, multidecadal, PDO, reconstruction

Citation: Hidalgo, H. G. (2004), Climate precursors of multidecadal drought variability in the western United States, Water Resour. Res., 40, W12504, doi:10.1029/2004WR003350.

\section{Introduction}

[2] Because of its geographic and climatologic characteristics, the western United States (Figure 1) is particularly vulnerable to severe and sustained droughts (SSDs). Historical documents, proxy climate indicators, and meteorological records revealed that during the past 2000 years, the western United States and surrounding areas have experienced widespread and prolonged droughts, with devastating impacts on societal and ecological systems [Woodhouse and Overpeck, 1998; Weakly, 1965; Meko et al., 1995; GrissinoMayer, 1996]. Furthermore, analyses of paleoclimatic proxy indicators have shown that the most severe droughts of the twentieth century (the 1930's Dust Bowl and the 1950's Drought) are overshadowed by preinstrumental droughts that occurred as recently as the late sixteenth century [Woodhouse and Overpeck, 1998]. The "late sixteenth century megadrought" (Figure 2) is evident from circa 1572 to 1599 in many tree-ring climate reconstructions throughout the western United States and is considered the most severe drought in this region, at least, for the past 500 years [Stahle et al., 2000, 2003]. Among other cata-

Copyright 2004 by the American Geophysical Union. 0043-1397/04/2004WR003350\$09.00 strophic consequences, this drought may have exacerbated the collapse of native population in Mexico by magnifying the impact of infectious diseases through changes in ecological and sociological systems that depend on freshwater supply [Acuña-Soto et al., 2002].

[3] Drought conditions have been generally associated with low-frequency components of the climate system [Namias, 1983]. Recent studies of instrumental records have shown that low-frequency variations of the North Pacific and Atlantic Ocean temperature variations explain large parts of the low-frequency drought and precipitation variability in the United States [Mantua et al., 1997; Enfield et al., 2001; Gray et al., 2003; McCabe et al., 2004]. North Pacific climate variations are indexed by the first principal component of sea surface temperature (SST) anomalies in the North Pacific (poleward of $20^{\circ} \mathrm{N}$ ), known as the Pacific Decadal Oscillation (PDO) [Mantua et al., 1997]. A smoothed index of the mean SSTs in the North Atlantic Ocean (poleward of the equator), known as the Atlantic Multidecadal Oscillation (AMO) [Enfield et al., 2001], indexes North Atlantic low-frequency variations. The positive phase of the AMO was associated with increased probabilities of drought in the western United States by McCabe et al. [2004]. According to these authors, when the 


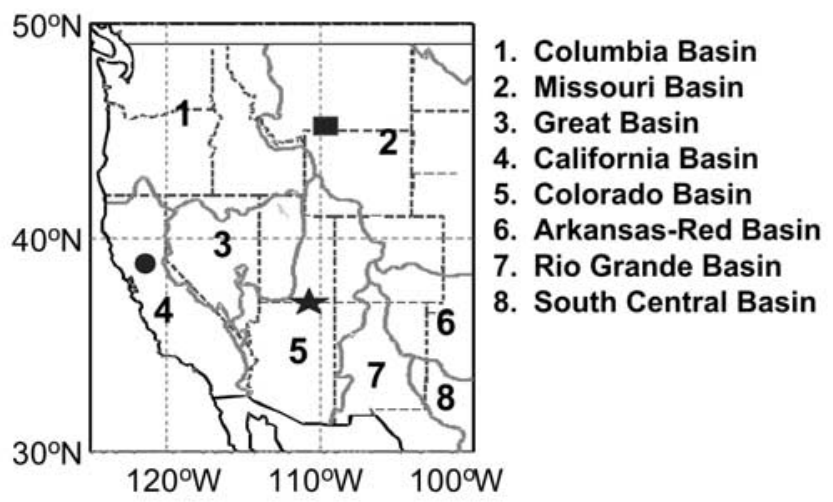

Figure 1. Major water resources regions of the western United States and location of streamflow gages on the Upper Colorado River at Lees Ferry (star), the Sacramento River at Sacramento (circle), and the Yellowstone River at Corwin Springs (square).

western United States is in a drought mode (AMO positive), the sign of the PDO determines if the drought center is more probably to be located in the northern (PDO positive) or the southern part (PDO negative) of the western United States. The interplay of the AMO and PDO in the production of western U.S. drought is consistent with the observation by Fye et al. [2003] that some paleodroughts have a spatial signature similar to the 1930's Dust Bowl (AMO positive and PDO positive), while others are similar to the 1950's Drought (AMO positive, PDO negative).

[4] In the present study, possible climate forcing mechanisms associated with paleodroughts of the past $\sim 500$ years (such as the late sixteenth century megadrought) will be identified and compared to twentieth century drought-producing mechanisms. Another objective is to determine whether western U.S. hydrologic variations have responded to similar large-scale climatic mechanisms in the past and in the twentieth century so that this information can be used to recognize similar extreme climate events in the future. The term "climate forcings" (or "mechanisms") is defined loosely here as the climate signals coming from particularly large regions (North Pacific, North Atlantic, and tropical Pacific) and characterized using simple indexes. However, these processes may be just an expression of even larger climate processes or can be related to more fundamental forcings (i.e., solar, lunar, volcanic).

\section{Data Sources}

[5] Several tree-ring reconstructions were used in this study in order to characterize low-frequency variations in the western United States (Table 1). These tree-ring reconstructions are readily available through the National Oceanic and Atmospheric Administration (NOAA) Paleoclimatology Data Bank. The information extracted using proxy climate indicators, such as the tree-ring reconstructions from Table 1, has a certain degree of representativeness of the reconstructed hydroclimatic variable (or teleconnection index). This representativeness is usually evaluated using statistics of the model's fit during the calibration period, given the typical limitations and assumptions of the tree-ring reconstruction methods [Fritts, 1991]. In this study, the reconstructions selected are thought to be considerably representative of long-term climate variations according to the statistics reported by the authors of these reconstructions (Table 1). Unfortunately, independent validations of tree-ring reconstructions, for example, based on information from other proxy records (i.e., ice cores, lake sediments, marine cores), are not commonly included as part of tree-ring reconstruction studies, and in many cases these validations are impossible due to different sensitivities and temporal resolution of the proxies or to the lack of data. Tree-ring reconstructions are based on the assumption that the empirical relationship established between tree-ring
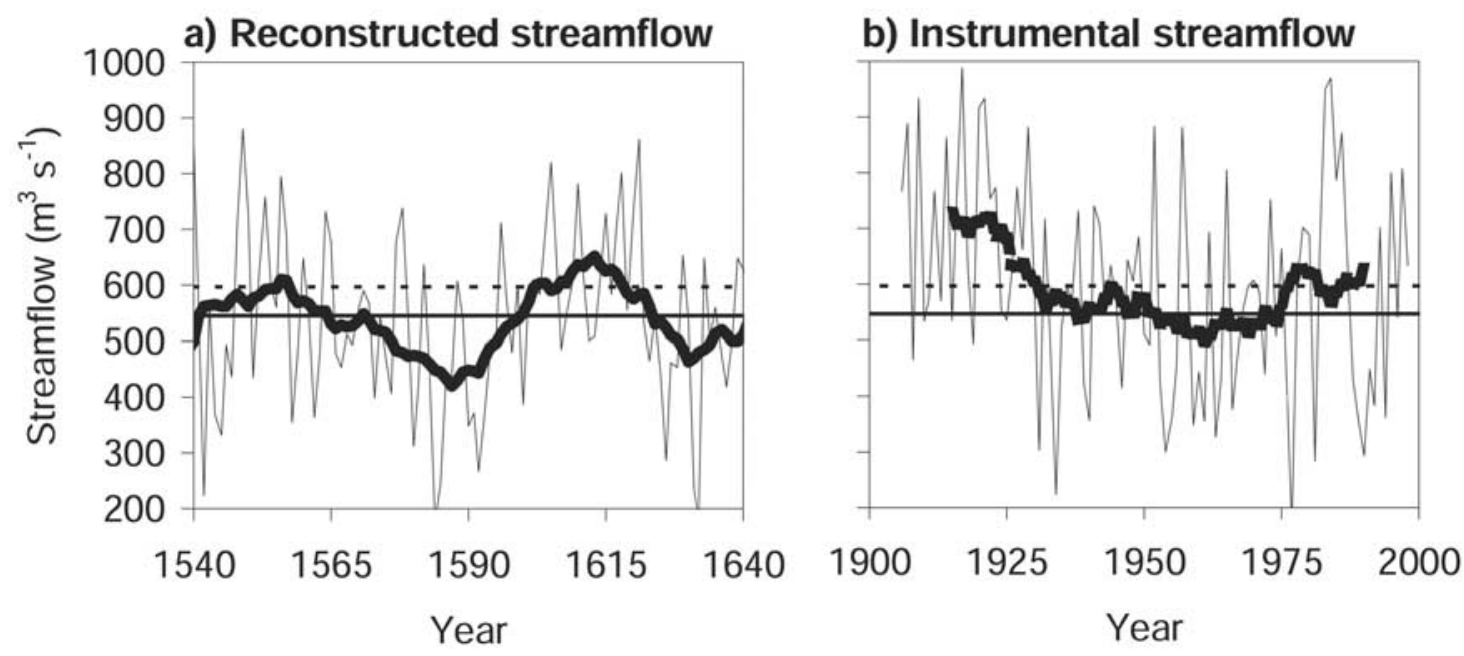

Figure 2. The "late sixteenth century megadrought" as recorded in a tree-ring reconstruction of mean annual average streamflow of the Colorado River at Lees Ferry (left), and naturalized annual streamflow record from 1906 to 1998 (right). Thick lines represent the 20-year moving averages of both time series. The solid horizontal lines represent the long-term mean of the streamflow reconstruction, and the dashed lines represent the mean of the instrumental records. 
Table 1. Proxy Records Used in This Study

\begin{tabular}{|c|c|c|c|c|}
\hline Variable Reconstructed & Season & Initial Year & Ending Year & Source \\
\hline \multicolumn{5}{|c|}{ Tree Ring Reconstructions } \\
\hline Streamflow of the Colorado River at Lees Ferry & annual & 1512 & 1961 & Stockton and Jacoby [1976] \\
\hline Streamflow of the Sacramento River at Sacramento & annual & 869 & 1977 & Meko et al. [2001] \\
\hline Streamflow of the Yellowstone River at Corwin Springs & annual & 1706 & 1977 & Graumlich et al. [2003] \\
\hline Pacific Decadal Oscillation & Nov. to Mar. & 1661 & 1991 & Biondi et al. [2001] \\
\hline Southern Oscillation Index & winter & 1706 & 1977 & Stahle et al. [1998] \\
\hline Gridded Palmer Drought Severity Index & summer & 1525 & 1975 & Cook et al. [1999] \\
\hline Atlantic Multidecadal Oscillation & annual & 1567 & 1990 & Gray et al. [2004] \\
\hline \multicolumn{5}{|c|}{ Other Proxies } \\
\hline Quelccaya ice accumulation & annual & 470 & 1984 & Thompson and Mosley-Thompson [1989] \\
\hline
\end{tabular}

growth and climate does not change significantly over time [Fritts, 1991]. In addition, tree-ring reconstructions are less accurate at earlier times, as the average ring width during these times is usually calculated using fewer trees [Fritts, 1991; Hidalgo et al., 2000, 2001].

[6] A tree-ring reconstruction of annual streamflow of the Colorado River at Lees Ferry, Arizona, from 1512 to 1961 was obtained from Stockton and Jacoby [1976]. Lees Ferry is located at the outflow of the Upper Colorado River Basin (UCRB; Figure 1). The UCRB is the most important basin in terms of water supply for much of the western United States. A reconstruction of annual streamflow in the Upper Yellowstone River at Corwin Springs, Montana, from 1706 to 1977 was obtained from Graumlich et al. [2003] and was used to characterize variations in the interior northern part of the western United States. Tree-ring reconstructions are typically based on relations of tree-ring thickness (or density) indexes to climatic parameters (i.e., streamflow, precipitation, temperature). Graumlich et al.'s [2003] streamflow reconstruction, however, uses available tree-ring reconstructions of the PDO [Biondi et al., 2001] and the Southern Oscillation index (SOI) [Stahle et al., 1998] indices, along with tree-ring chronologies, to reconstruct the annual streamflow of the Yellowstone River. The tree-ring reconstruction of the annual streamflow of the Sacramento River at Sacramento, California, from 869 to 1977 [Meko et al., 2001] was used for the characterization of drought variability in coastal regions. The locations of the streamflow reconstructions are shown in Figure 1. These locations were selected to match the centers of action of the PDSI subregions that will be identified later using rotated principal component (RPC) analysis.

[7] A reconstruction of the PDO from 1661 to 1991 was obtained from Biondi et al. [2001]. These data were used to index long-term climate variations in the North Pacific. A reconstruction of the winter SOI, the atmospheric component of El Niño-Southern Oscillation (ENSO), was obtained from Stahle et al. [1998]. This SOI reconstruction from 1706 to 1977 was used to characterize tropical Pacific climate influences. Annual ice accumulation totals at Quelccaya ice cap in Peru [Thompson and Mosley-Thompson, 1989] were also used to verify ENSO influences. A reconstruction of the AMO index from 1567 to 1990 using North American and European tree-ring chronologies was obtained from Gray et al. [2004] and used to validate connections between western U.S. drought and North Atlantic climate. Gridded $(2 \times 3$ degree $)$ reconstructions of the summer Palmer Drought Severity Index (PDSI) for the western United States from 1525 to 1975 were obtained from Cook et al. [1999]. These PDSI series were used to determine spatial characteristics of low-frequency variations in the western United States.

[8] Historical streamflow data from the Colorado, Sacramento, and Yellowstone Rivers were obtained from the U.S. Geological Survey (USGS) [2004] and the U.S. Bureau of Reclamation (USBR) [1998]. Time series of the PDO and SOI during the twentieth century were obtained from updated versions of the series of Mantua et al. [1997] and Allan et al. [1991], respectively. Following Enfield et al. [2001], the AMO index for the twentieth century was computed by averaging the North Atlantic SSTs (poleward of the equator) gridded data $(5 \times 5$ degree $)$ from an extended version of the Kaplan et al. [1998] SST data set and then filtering the index using 20-year moving averages.

[9] Many of the time series in this study were smoothed by 20 -year moving averages based on McCabe et al. [2004] in order to filter seasonal to multidecadal variations. As a result, the time series were shortened by 19 years. In addition, the smoothing process reduces the number of degrees of freedom used in the determination of the statistical significance of correlation coefficients. For this reason, the statistical significances of all correlation coefficients were estimated using Monte Carlo techniques [McCabe et al., 2004]. The use of a 20-year low-pass Butterworth filter [see Mitra and Kaiser, 1993] instead of the smoothing of the 20-year moving averaging did not alter significantly the results (not shown). Finally, it is noteworthly that tree-ring reconstructions shown in Table 1 are produced for different seasons. It is assumed here that the smoothed versions (20-year running averages) of these reconstructions contain mainly the signature of low-frequency climatic (and tree-ring growth) variations present in all seasons, such that intraseasonal differences (and higher-frequency variations) can be ignored.

\section{Low-Frequency Climate Variations in the Western United States}

[10] Spectral analysis of the reconstructed PDSI grids [Cook et al., 1999] covering the western United States for different epochs shows significant changes in the dominant frequency of PDSI variations through time (Figure 3 ). There 


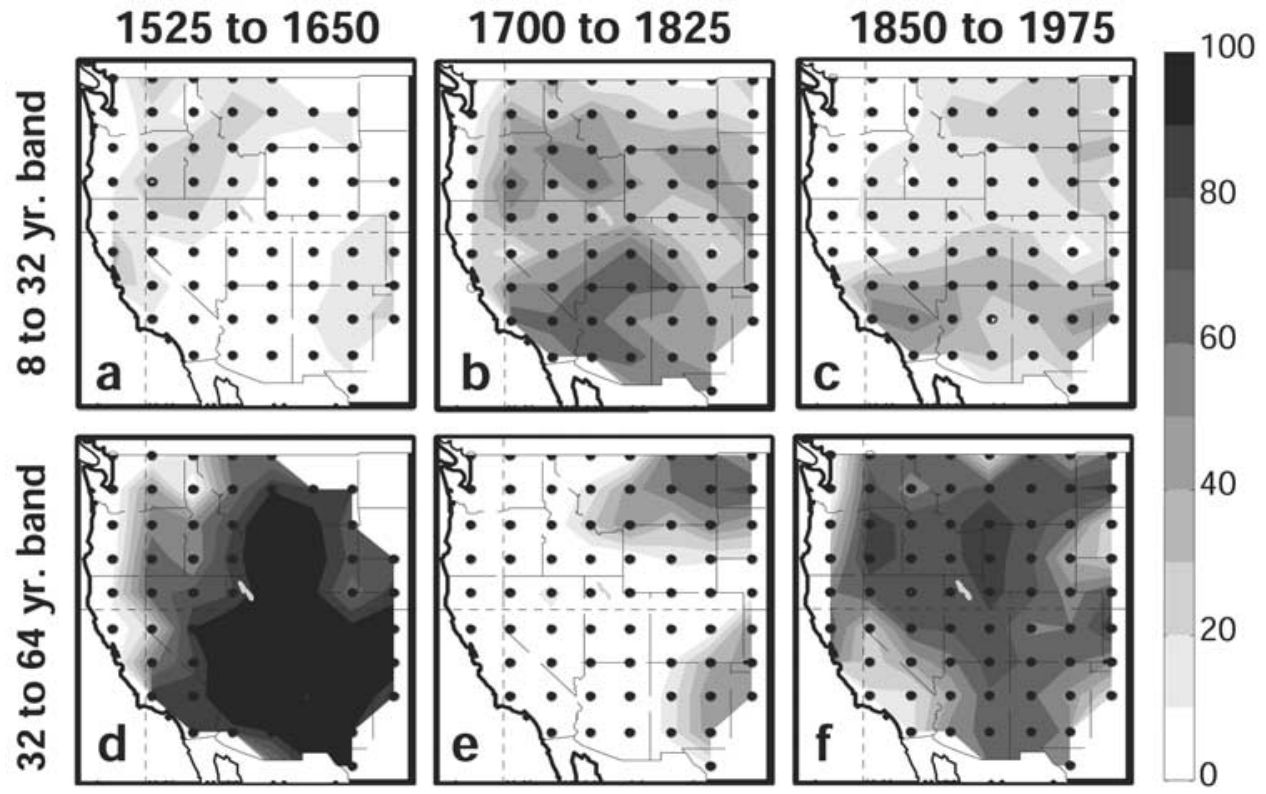

Figure 3. Percentage of the total power spectral density (above red-noise spectrum) contained in two bands that capture roughly bidecadal and pentadecadal cycles in tree-ring reconstructed PDSI, for each of three 125-year epochs.

are three distinct epochs (with correspondingly distinct spectral characteristics) in the variability of PDSI from 1525 to 1975 .

[11] Pentadecadal (and longer) PDSI variations provided a large fraction of the total drought variance in the interior western United States during an early epoch (circa 15251650) when the bidecadal PDSI oscillations were subdued (Figures $3 \mathrm{a}$ and $3 \mathrm{~d}$ ). Spectral analyses of millennial reconstructions suggest that pentadecadal (and longer) oscillations have been a common feature of the variability of the climate of the western United States for the past 2000 years [Hidalgo and Dracup, 2004; Grissino-Mayer, 1996].

[12] Bidecadal PDSI oscillations are dominant in the 200 years from circa 1650 to 1850 , as evidenced in the spectral characteristics of the 125-year window from 1700 to 1825 (Figure $3 b$ ). The bidecadal PDSI cycle during this epoch is particularly strong in the Southwest (e.g., Lower Colorado River Basin) and Southern California (Figures 3b and $3 \mathrm{e}$ ), while the largest contribution of the pentadecadal PDSI cycle to the total spectral density is confined to parts of the Upper Missouri River Basin (Figure 3e). In the most recent 150-year epoch analyzed (1850-1975), pentadecadal PDSI oscillations prevail again across the western United States, with the exception of southern California, which is still dominated by bidecadal PDSI variations (Figures 3c and 3f).

[13] The spatial extent of the pentadecadal variations during the earliest of these epochs is similar but not identical the most recent epoch. Figure 3 registers the occurrence of both drought and pluvials, but the spatial extent of the early pentadecadal variations is probably dominated by the late sixteenth century megadrought (Figure 3d). In contrast, the pentadecadal variations during the most recent epoch affect more strongly the northern internal regions (Figure $3 \mathrm{f}$ ). The most severe low-frequency drought in the past 150 years in the western United States is the 1930's Dust Bowl drought (1925-1943). The plot of Figure $3 \mathrm{f}$ is less identifiable with a particular drought event, although it shows some similarity with the spatial extend of the Dust Bowl (as recorded in instrumental summer PDSI).

[14] It should be mentioned that the spectral bands in Figure 3 were selected with the purpose of (roughly) capturing bidecadal and pentadecadal oscillations associated with North Pacific climate variations [Hidalgo and Dracup, 2003, 2004; Minobe, 1997]. The "bidecadal band" contains PDSI variations with a periodicity of 8 to 32 years, while the "pentadecadal band" captures oscillations with a periodicity from 32 to 64 years. This suggests that droughts and pluvials with a periodicity of 8 years or more can be clearly identified in Figure 3. In following sections, the PDSI data will be smoothed using 20-year moving averages. In these cases, only the very low frequency (periodicities close to 20 years or more) variations can be easily identified using the smoothed PDSI data. Individual droughts of considerable duration (but much less than 20 years) may not be easily identifiable in the smoothed data. However, inspection of the data corroborated that many large droughts (of durations significantly less than 20 years) are usually caused by the contribution of "background" sustained low PDSI (or streamflow) conditions, due to the low-frequency component of the climate, combined with deep incursions of extremely low PDSI (or streamflow) values during the most critical years of the drought (Figure 2).

[15] In the circa 1850-1975 epoch, much of the hydroclimatic variation in the western United States took the form of significant pentadecadal (and longer) oscillations (Figure 3). This suggests that SSDs have been more likely to occur in this period than in the previous 200-year epoch (circa 1650-1850). Fortunately, the amplitudes and periodicities of the pentadecadal variations in the most recent epoch are smaller than the amplitudes and periodicities 
a) RPC1 (31\%)

$50^{\circ} \mathrm{N}$
$40^{\circ} \mathrm{N}$
$30^{\circ} \mathrm{N}$

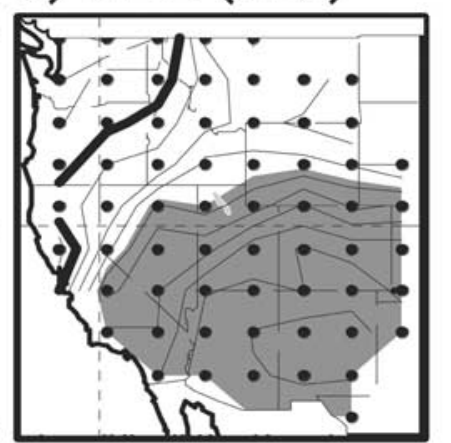

$120^{\circ} \mathrm{W}$ b) RPC2 (24\%)

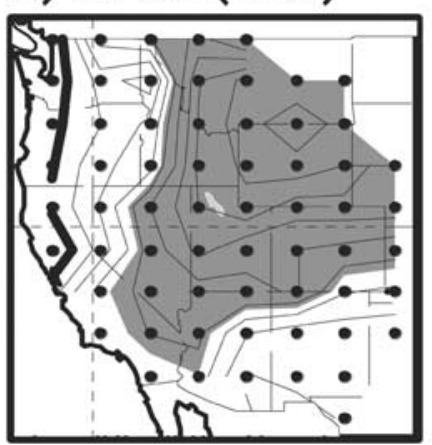

$100^{\circ} \mathrm{W}$ c) RPC3 (19\%)

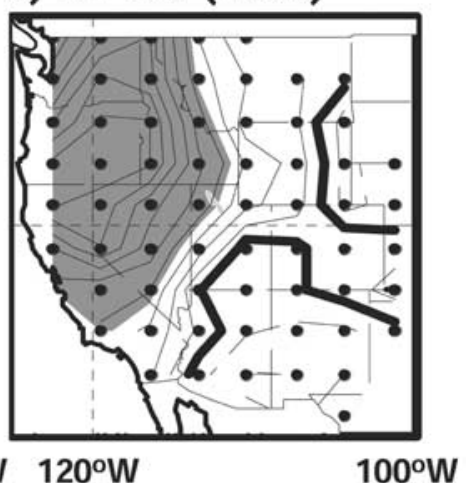

Figure 4. Loadings of the first three rotated principal components (RPCs) of smoothed (20-year moving average), gridded tree-ring reconstructions of the PDSI from 1536 to 1967. The contours shown represent the correlation of the smoothed original data with the RPCs scores. Contours every 0.1, positive (negative) correlation are shown with solid (dashed) lines, while the zero correlation contour is shown as a thick dashed line. The shaded area represents correlations significant at the 0.05 level obtained through Monte Carlo analyses. The fraction of the explained variance of each RPC is shown in parentheses.

during the previous epoch of pentadecadal variations centered circa 1600. This difference will be studied in the following sections.

\section{Climate Forcings}

[16] In order to isolate the climate forcing signals in lowfrequency western U.S. hydroclimatic variations, a RPC analysis was performed on the smoothed gridded PDSI reconstruction from 1525 to 1975 . Loadings of the first three PDSI RPCs $(74 \%$ variance) are shown in Figure 4 , and the RPCs scores are shown in Figure 5. The RPCs derived here for the western U.S. grid cells were similar to several of the PDSI RPCs for the entire grid (the conterminous United States) calculated by Cook et al. [1999]. RPC1 ( $31 \%$ of the variance) is strongly correlated with the PDSI variations over most of the southwestern United States including the Colorado River basin (Figure 4a). RPC2 (24\%) represents mostly PDSI variability in the Yellowstone River Basin and parts of the Upper Colorado River Basin and the Upper Missouri River Basin (Figure 4b). RPC3 (19\%) is correlated with PDSI varia-

a)

RPC1 (31\%) PDSI (this analysis) _ PDO (Biondi et al. 2001) - PDO (Mantua et al. 1997)

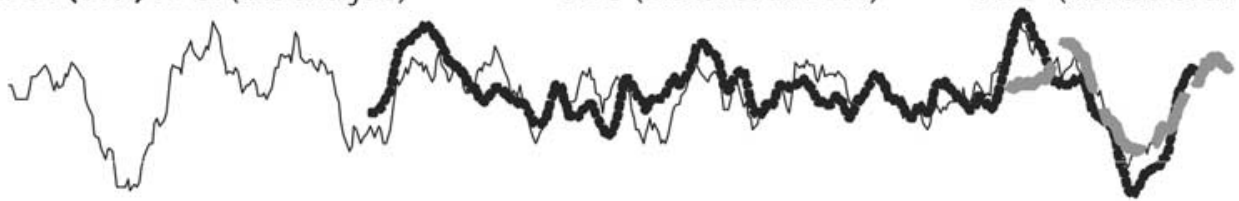

b) - RPC2 (24\%) PDSI (this analysis)

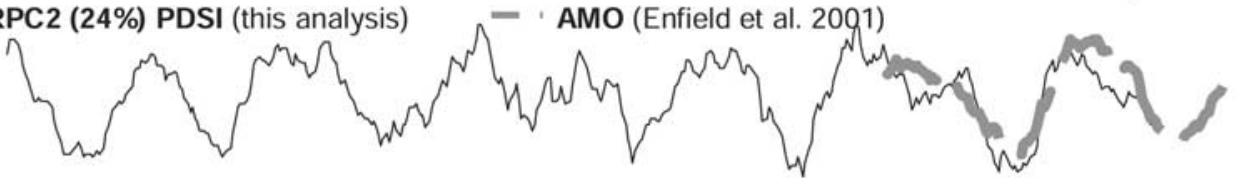

c)

- RPC3 (19\%) PDSI (this analysis) - SOI (Stahle et al. 1998) - SOI (Allen et al. 1998)

.... Quelccaya ice accumulation (Thompson and Mosley-Thompson 1989)

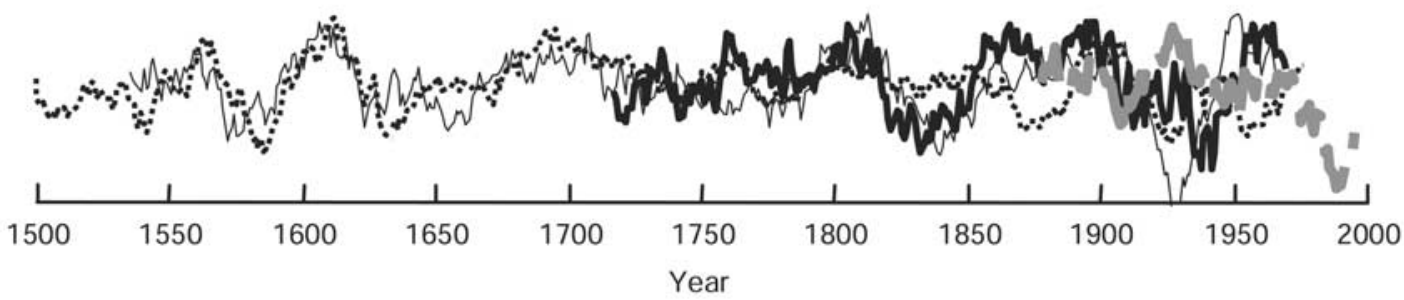

Figure 5. Time series of RPC scores of the first three rotated principal components (RPCs) extracted from smoothed gridded tree-ring reconstructions of the PDSI, compared with smoothed reconstructions (thick solid lines) and instrumental records (shaded thick lines) of several climate indices. The explained variance of each RPC is shown in parentheses. 


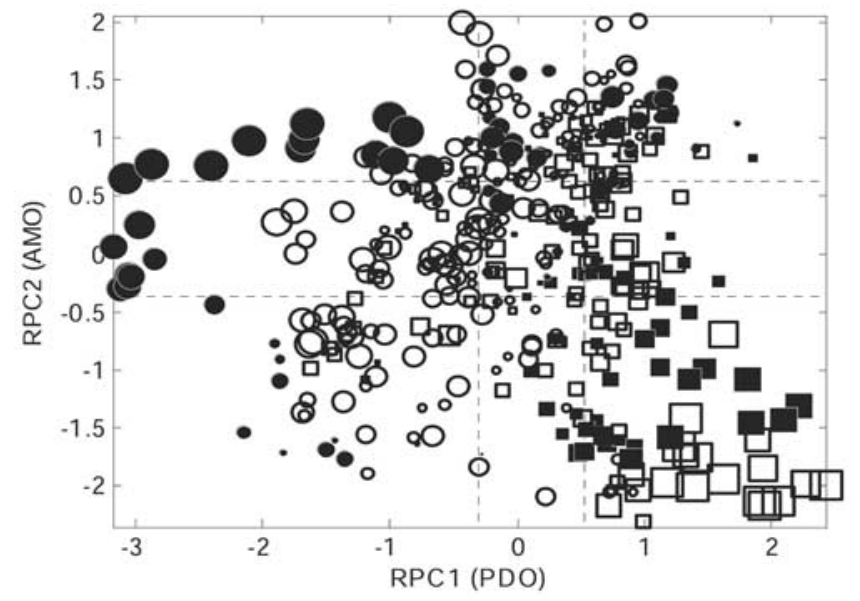

Figure 6. Standardized values of a tree-ring reconstruction of the Colorado River streamflow at Lees Ferry from 1536 to 1953, classified according to the first two RPCs of Figure 5, which are thought to be related to PDO and AMO, respectively. Square (circle) symbols indicate pluvials (droughts). The streamflow reconstruction was smoothed using 20 -year running averages. The sizes of the symbols are proportional to the magnitude of the streamflow anomalies. The largest symbols represent anomalies of approximately 3 standard deviations. Data from 1536 to 1650 are shown with solid symbols. The terciles of the RPCs are shown as vertical and horizontal lines.

tions in the Pacific Northwest, northern California, and the Great Basin and is weakly to moderately anticorrelated with PDSI variations in the southwestern United States (Figure 4c).

[17] The PDSI RPC scores are significantly correlated with large-scale climate indices during the instrumental period (1900-1975), indicating significant influence from Pacific and Atlantic climate processes (Figure 5). RPC1 is strongly correlated with the PDO index $(r=0.82, p<0.05)$ during the instrumental period and, before that, matched very closely a smoothed version of the PDO reconstruction by Biondi et al. [2001] $(r=0.74, p<0.01)$.

[18] RPC2 is significantly correlated with annual AMO index $(r=0.88, p<0.05)$ during the instrumental period, and overall has periodicities similar to North Atlantic SST signals mentioned in other studies [Kushnir et al., 1997; Tourre et al., 1999; Delworth and Mann, 2000]. Strongest loadings of RPC2 are in the Upper Missouri basin, a basin known to be influenced by the AMO [Enfield et al., 2001]. The regularity shown by RPC2 is remarkable, with a welldefined periodicity of about 51 years and almost no spectral power at other periodicities. In addition, a recent tree-ring reconstruction of the AMO index [Gray et al., 2004], using an independent network of tree-ring chronologies, correlated significantly with RPC2 $(r=0.54, p<0.01)$. However, the Gray et al. [2004] reconstruction did not exhibit the same regularity as RPC2. It is possible that RPC2 could contain the PDSI effects in the western United States from pentadecadal climate oscillations in both the North Atlantic and the North Pacific [Delworth and Mann, 2000; Minobe, 1997].

[19] RPC3 correlated moderately with a smoothed version of the SOI $(r=0.71, p<0.05)$ during the instrumental period; however, the very low values of RPC3 around 1930 were not matched by a similar SOI negative period. In the longer term, a tree-ring reconstruction of the SOI [Stahle et al., 1998] and a band-passed Butterworth-filtered series (periodicities between 20 and 120 years) of ice accumulation totals at Quelccaya [Thompson and Mosley-Thompson, 1989] were similar to RPC3, supporting the hypothesis of a direct tropical Pacific connection (Figure 5c). However, notice that although the year-to-year SOI reconstruction by Stahle et al. [1998] matches the winter SOI raw observations (without smoothing) well $(r=0.70, p<$ 0.01 ), the low-frequency (smoothed) components do not match well. A possible reason for the lack of correlation of low-frequency observed and reconstructed SOI could be related to the contributions from low-frequency tree-ring growth variations unrelated to ENSO.

[20] It is generally accepted that tropical and North Pacific climate variations (indexed by the SOI and PDO, respectively) are closely related to each other [Zhang et al., 1996, 1997; Newman et al., 2003]; however, the RPCs in Figure 5 are constructed to be uncorrelated (from 1925 to 1975), making RPC1 (representing PDO effects) and RPC3 (representing SOI effects) orthogonal to each other. Therefore the identification of RPCs is achieved at the expense of losing some of the characteristics (i.e., intercorrelation) known to exist between the main teleconnection signals. An indication of this loss of information is that the spatial signature of ENSO in western U.S. climate identified through many studies using instrumental data [e.g., Redmond and Koch, 1991; Cayan and Webb, 1992; Cayan et al., 1999; Dettinger et al., 2000; Piechota et al., 2001; Brown and Comrie, 2004; Hidalgo and Dracup, 2003] is somewhat different to the pattern shown in Figure 4.

[21] The historical values of the climate indices, PDO, SOI, and AMO, are used here only to name the RPCs and to suggest the apparent origin of the strongest controlling factor of drought variability in the western United States during the instrumental period. However, the teleconnections of these remote indexes and local tree-ring growth may change over time and the RPCs may be forced differently by large-scale climate mechanisms. This does not invalidate the RPCs of Figure 5 but may express stronger or weaker connections during certain periods with the climatic processes that were used to name them. In addition, as was mentioned previously, the RPCs are only one structured (arbitrary) representation of the PDSI data set, and as such have certain limitations. This representation is not necessarily identical to the dynamical modes of variation the system [Newman and Sardeshmukh, 1995].

\subsection{Forcings of SSDs in the Southwestern United States}

[22] Low-frequency drought variations in the southwestern United States are most represented by the contributions of RPC1 and RPC2, thought to be related to the PDO and the AMO, respectively (Figure 5). In Figure 6, the standardized values of the tree-ring streamflow reconstruction of the Colorado River at Lees Ferry are classified according to RPC1 (PDO) and RPC2 (AMO). Although the middle streamflow values scattered considerably, most of the largest pluvials (square symbols) of the fifteenth, sixteenth, and twentieth centuries are associated with higher-than-normal 


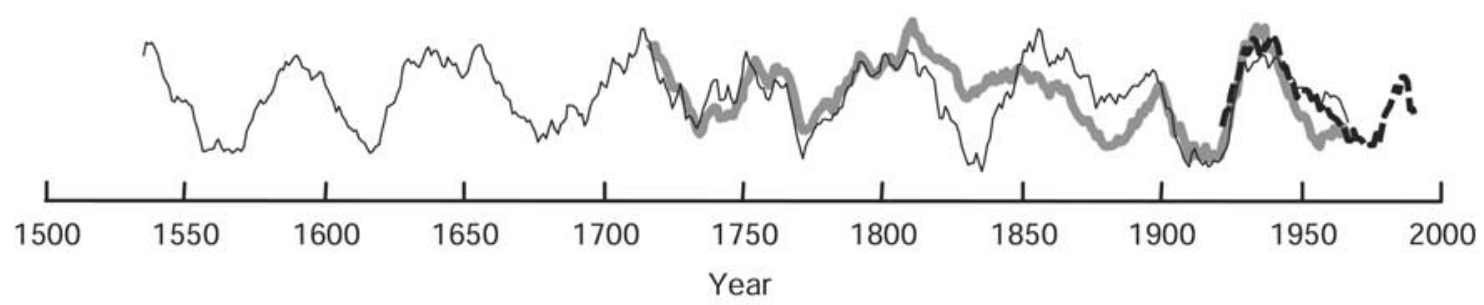

Figure 7. Time series of reconstructions (gray thick line) and measurements (black dashed line; USGS [2004]) of annual streamflow in the Yellowstone river at Corwin Springs (inverted), compared to the PDSI RPC2 scores thought to represent low-frequency variations of the AMO (thin black line). All time series were standardized and smoothed using a 20 -year running average.

positive PDO and lower-than-normal AMO indices. Conversely, many of the extremely dry years of the late sixteenth century megadrought are characterized by higher-than-normal AMO indices and strongly negative PDO conditions (large solid circles). In addition, a few of the extremely dry years of the megadrought had a combination of normal AMO years and extremely negative PDO values unseen at any other time of the record. The combination of low PDO and high AMO was also observed during the 1950's Drought as recorded in instrumental records [McCabe et al., 2004]. However, in terms of the smoothed streamflow reconstruction of the Upper Colorado River, the $1950 \mathrm{~s}$ was a period close to the long-term, reconstructed, mean (Figure 2). The streamflow average based on the instrumental record, however, defines the 1950 s as a dry period, contrasting with the long wet spell centered around the 1920s (Figure 2). From Figure 6 it can be concluded that the late sixteenth century megadrought had much stronger forcings than in any other period of the last 500 years. The low-frequency component played an important part of the developing of this megadrought (Figures 2 and 6).

[23] The period dominated by the bidecadal cycles (circa $1650-1850)$ of the North Pacific climate, was the period with most of the near-normal streamflows in the Colorado
River (Figures 5 and 6). In contrast to the extreme droughts and pluvials of the pentadecadal epochs, these near-normal flows are weakly correlated with RPC1 (PDO) and RPC2 (AMO). The climatic mechanisms that controlled the variability of the western U.S. PDSI during this epoch are unknown.

\subsection{Forcings of SSDs in the Northern Rocky Mountains}

[24] Hydrologic variations in the northern Rocky Mountains and parts of the Upper Colorado River Basin are significantly affected by the AMO [McCabe et al., 2004; Enfield et al., 2001]. For example, a reconstruction of annual streamflow of the Yellowstone River at Corbin Springs by Graumlich et al. [2003] is significantly correlated $(r=-0.60, p<0.01)$ with the variations of RPC2 (AMO) from 1717-1967, suggesting that low-frequency variations from the Atlantic control a large part of the lowfrequency hydrologic variability in this basin (Figure 7). The low-frequency components of Yellowstone River streamflow represent on average $14 \%$ of the total variance of the reconstruction, which is about twice the variance found for the reconstructions of the Colorado and the Sacramento rivers (Table 2). These significant lowfrequency hydrologic fluctuations define sustained droughts

Table 2. Percentage of Variance Contained in the Smoothed (20-Year Running Average) Reconstructed Streamflow $\left(Q_{\text {low }}\right)$ Compared With the Total Variance of the Raw Reconstruction $\left(Q_{\text {raw }}\right)$ Time Series at Different Epochs

\begin{tabular}{|c|c|c|}
\hline Period & $\operatorname{Var}\left(Q_{\text {low }}\right) / \operatorname{Var}\left(Q_{\text {raw }}\right), \%$ & Notes \\
\hline \multicolumn{3}{|c|}{ Annual Colorado River Streamflow at Lees Ferry [Stockton and Jacoby, 1976] } \\
\hline $1523-1650$ & 10 & $\begin{array}{l}\text { multidecadal epoch ("sixteenth century } \\
\text { megadrought" epoch) }\end{array}$ \\
\hline $1650-1850$ & 3 & bidecadal epoch \\
\hline $1850-1953$ & 12 & multidecadal epoch \\
\hline $1523-1953$ & 8 & total record \\
\hline \multicolumn{3}{|c|}{ Annual Yellowstone River Streamflow at Corwin Springs [Graumlich et al., 2003] } \\
\hline $1523-1650$ & no data & \\
\hline $1771-1850$ & 7 & bidecadal epoch \\
\hline $1850-1969$ & 16 & multidecadal epoch \\
\hline $1771-1969$ & 14 & total record \\
\hline \multicolumn{3}{|c|}{ Annual Sacramento River Streamflow at Sacramento [Meko et al., 2001] } \\
\hline $1523-1650$ & 5 & $\begin{array}{l}\text { multidecadal epoch ("sixteenth century } \\
\text { megadrought" epoch) }\end{array}$ \\
\hline $1650-1850$ & 4 & bidecadal epoch \\
\hline $1850-1969$ & 6 & multidecadal epoch \\
\hline $1880-1969$ & 7 & total record \\
\hline
\end{tabular}


Table 3. Relative Magnitude (Severity/Duration) of the Three Largest Droughts as Recorded in Smoothed (20-Year Running Averages) Reconstructed Streamflow for Selected Rivers in the Western United States ${ }^{\mathrm{a}}$

\begin{tabular}{|c|c|c|c|c|c|c|}
\hline Rank & Initial Year & Ending Year & Severity ( $\sigma$ units) & Duration, years & Magnitude & Comment \\
\hline \multicolumn{7}{|c|}{ Annual Colorado River Streamflow at Lees Ferry [Stockton and Jacoby, 1976] } \\
\hline 1 & 1572 & 1599 & -12.43 & 28 & -0.44 & late sixteenth century megadrought \\
\hline 2 & 1770 & 1788 & -5.46 & 19 & -0.29 & \\
\hline 3 & 1875 & 1901 & -7.46 & 27 & -0.28 & \\
\hline \multicolumn{7}{|c|}{ Annual Yellowstone River Streamflow at Corwin Springs [Graumlich et al., 2003] } \\
\hline 1 & 1925 & 1943 & -10.35 & 19 & -0.54 & 1930’s Dust Bowl \\
\hline 2 & 1714 & 1726 & -5.37 & 13 & -0.41 & \\
\hline 3 & 1784 & 1827 & -17.32 & 44 & -0.39 & \\
\hline \multicolumn{7}{|c|}{ Annual Sacramento River Streamflow at Sacramento [Meko et al., 2001] } \\
\hline 1 & 1532 & 1551 & -6.65 & 20 & -0.33 & \\
\hline 2 & 1916 & 1942 & -8.40 & 27 & -0.31 & \\
\hline 3 & 1835 & 1857 & -5.12 & 23 & -0.22 & \\
\hline
\end{tabular}

${ }^{\text {a }}$ Severity is defined as the summation of the total standardized deficit during each drought. Duration is the number of years presenting negative anomalies. Magnitude is the severity divided by the duration [Dracup et al., 1980]. Only droughts that started after 1525 are shown in this table. The reconstruction of the Yellowstone River streamflow started in 1706, and therefore droughts from 1525 to 1705 in this river were not considered.

and pluvials. For example, although the absolute magnitude and spatial extent of the late sixteenth megadrought is unrivaled in the interior western United States, relative to the variance of the time series, the 1930's Dust Bowl drought in the Yellowstone River was 23\% larger than the magnitude of the megadrought, as recorded in the Colorado River and Yellowstone River streamflow reconstructions (Table 3).

[25] The low-frequency PDO (RPC1) time series is nonsignificantly anticorrelated $(r=-0.27)$ with the Yellowstone River streamflow reconstruction by Graumlich et al. [2003] from 1717 to 1967 . However, examination of the time series reveals that the main discrepancy between the PDO (RPC1) and Yellowstone streamflow reconstructions occurred during the wet period from 1900 to 1925 (not shown). Assuming a negative correlation between the variables, the prolonged positive PDO period of 19001925 would be associated with a prolonged drought in the Yellowstone River; instead, a prolonged wet period occurred as shown in Figure 7. The 1900-1925 wet spell in the Yellowstone River is better explained by the prolonged negative phase of the AMO during this period (Figure 7). Excluding the years 1900-1925, the correlation between the low-frequency components of the PDO (RPC1) and annual streamflow reconstruction of the Yellowstone River at Corbin Springs is $-0.69(p<0.01)$. Another possible indication of North Pacific climate influence was the doubling of the explained variance after 1850 for the Yellowstone River streamflow reconstruction (Table 2), which suggests an influence from epochal changes in the spectral characteristics of the PDO discussed previously. However, a PDO reconstruction was used as one of the predictors in this particular streamflow reconstruction model [Graumlich et al., 2003], so the influence of the PDO was inevitable.

\subsection{Forcings of SSDs in the Pacific Northwest}

[26] The Pacific Northwest region, and to some extent the southwestern United States, are influenced by low-frequency oscillations related to ENSO (Figure 8). For example, the low-frequency components of a reconstruction of the annual streamflow of the Sacramento River at Sacramento [Meko et $a l ., 2001]$ and RPC3 (SOI) are strongly correlated ( $r=0.59$, $p<0.01)$. The late sixteenth century megadrought is not particularly severe in the Sacramento Basin, consistent with the hypothesis that this SSD was produced by the combination of AMO and PDO, which mainly affects the interior western United States.

\section{Concluding Discussion}

[27] The results presented here verify the existence of low-frequency climate oscillations playing an important role in the development of SSDs in the western United States

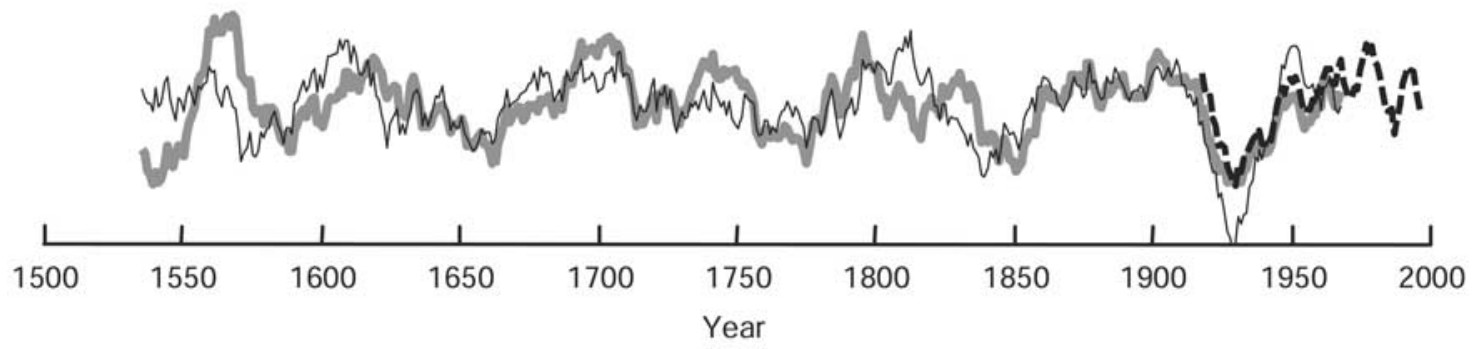

Figure 8. Time series of reconstructions (thick gray line) and measurements (black dashed line; USGS [2004]) of annual streamflow in the Sacramento River at Sacramento, compared to the PDSI RPC3 scores thought to represent low-frequency variations of the SOI (black thin line). All time series were standardized and smoothed using 20-year running averages. 
[Woodhouse and Overpeck, 1998; Namias, 1983]. In particular, the PDO and AMO are related to low-frequency variations of drought in certain regions of the interior western United States as previously noted by McCabe et al. [2004]. For example, it is argued that the late sixteenth century megadrought in the southwestern United States could have been produced by a persistent combination of strongly negative PDO and strongly positive AMO.

[28] Drought in the northern Rocky Mountains and the Upper Colorado River basin seem to be strongly dominated by the AMO (and to lesser extent to the PDO), yielding low-frequency hydrologic oscillations with large amplitude and making this region susceptible to SSDs. The drought with the largest magnitude during the past 250 years in the Yellowstone basin was the Dust Bowl (1925-1943), a period dominated by positive AMO (and positive PDO) conditions.

[29] In the most recent epoch analyzed (1850-1975), hydroclimatic variations in many parts of the western United States included significant pentadecadal (and longer) oscillations. This suggests that SSDs have been more likely to occur in this period than in the preceding 200-year epoch (1650-1850). Fortunately, the amplitudes and periodicities of the pentadecadal variations in the most recent epoch were smaller than the amplitudes and periodicities of a similar epoch of pentadecadal variations centered circa 1600 . Both epochs of pentadecadal climate variations responded (at least in part) to similar climatic forcing mechanisms, but differences between these two epochs could have been related to weaker forcings from large-scale climate mechanisms (indexed by the PDO and AMO) in the more recent period. Changes in the spectral characteristics of western U.S. PDSI and streamflow variations mirror similar changes in the spectral characteristics of North Pacific climate variations indexed by a PDO reconstruction [Biondi et al., 2001; Hidalgo and Dracup, 2004]. However, since the PDO reconstruction was based on tree rings located in the western United States, it is unknown whether these changes are truly related to North Pacific climate variability or to changes in the strength or nature of the climate teleconnections. Further independent verification with other North Pacific proxies (i.e., ice cores from Alaska) might allow verification of the persistence of the teleconnections. It is encouraging to note, however, that annual ice accumulation totals from the Quelccaya ice core in Peru [Thompson and Mosley-Thompson, 1989] also exhibit similar spectral changes (not shown), suggesting that the epochal reorganization of the spectral characteristics originates in the Pacific Basin. The reasons behind the change of dominant periodicities in the PDO are unknown but are related at least in part to natural climate variability [Hidalgo and Dracup, 2004].

[30] The presence of a very regular mode of PDSI variability in the western United States during the past 500 years, with a characteristic periodicity close to 51 years, is intriguing. Apparently, the mode is related to the AMO influence, although connections with pentadacadal climate variations from the Pacific cannot be discarded. Assuming (1) that this regularity is not a mathematical artifact of the RPCA, (2) that these variations are indeed associated with the AMO, and (3) that this mechanism is not affected by other effects (e.g., climate change), then the regularity exhibited by RPC2 and a switch toward a positive phase of the AMO in 1992 might foreshadow an increase in the possibility of droughts in the western United States during the next 10 years (a suggestion also implicitly made by McCabe et al. [2004]). This dire prospect depends also on future states of the PDO. Recent negative values of the PDO reinforce the chances of droughts centered in the southwestern United States. However, as was seen in this study, the PDO is not generally as regular as the AMO, and therefore future tendencies of the PDO are more uncertain. If both the AMO and the PDO become significantly positive, there is an increased possibility of drought, but it would be centered mostly in the northern Rocky Mountains. Regardless, the reasonable prospect of a drought in the western United States deserves consideration to minimize potential devastating effects to water resources in the western states.

[31] Other questions regarding drought producing process in the western United States still remain: How will the 21th century teleconnections be affected by anthropogenic climate change? How do feedbacks between drought conditions in the land interact with ocean temperatures to sustain dry conditions? What are the atmospheric circulations associated with the production of multidecadal SSDs? Are the pentadecadal oscillations in the North Atlantic and North Pacific related? Why are North Pacific climate variations less regular than those in the North Atlantic? Climate models and future paleoclimatic studies may provide the answers to some of these questions.

[32] Acknowledgments. This work is funded by grants from the California Energy Commission through the California Climate Change Center at Scripps and by the United States Department of Energy. Special thanks to Mike Dettinger for his thoroughly review and comments to this manuscript. The author is obliged to Dan Cayan, Julio Betancourt, Greg McCabe, David Meko, Steve Gray, Tom Piechota, and two anonymous reviewers for their comments to several versions of this work. The author gratefully acknowledges the contributors of NOAA's Paleoclimatology Data Bank for making their tree-ring data and comprehensive dendroclimatic reconstructions available for this type of study.

\section{References}

Acuña-Soto, R., D. W. Stahle, M. K. Cleaveland, and M. D. Therrell (2002), Megadrought and megadeath in 16th century Mexico, Emerging Infec. Dis., 8(4), 360-362.

Allan, R. J., N. Nicholls, P. D. Jones, and I. J. Butterworth (1991), A further extension of the Tahiti-Darwin SOI, early SOI results and Darwin pressure, J. Clim., 4, 743-749.

Biondi, F., A. Gershunov, and D. R. Cayan (2001), North Pacific decadal climate variability since $1661, \mathrm{~J}$. Clim., 14, 5-10.

Brown, D. P., and A. C. Comrie (2004), A winter precipitation "dipole" in the western United States associated with multidecadal ENSO variability, Geophys. Res. Lett., 31, L09203, doi:10.1029/2003GL018726.

Cayan, D. R., and R. H. Webb (1992), El Niño/Southern Oscillation and streamflow in the western United States, in El Niño Historical and Paleoclimatic Aspects of the Southern Oscillation, edited by H. F. Diaz and V. Markgraf, pp. 29-68, Cambridge Univ. Press, New York.

Cayan, D. R., K. T. Redmond, and L. G. Riddle (1999), ENSO and hydrologic extremes in the western United States, J. Clim., 12, $2881-2893$.

Cook, E. R., D. M. Meko, D. W. Stahle, and M. K. Cleaveland (1999), Drought reconstructions for the continental United States, J. Clim., 12, $1145-1162$.

Delworth, T. L., and M. E. Mann (2000), Observed and simulated multidecadal variability in the Northern Hemisphere, Clim. Dyn., 16, 661676.

Dettinger, M. D., D. R. Cayan, G. M. McCabe, and J. A. Marengo (2000), Multiscale streamflow variability associated with El Niño/ Southern Oscillation, in El Niño and the Southern Oscillation-Multi- 
scale Variability and Global and Regional Impacts, edited by H. F. Diaz and V. Markgraf, chap. 5, pp. 113-146, Cambridge Univ. Press, New York.

Dracup, J. A., K. S. Lee, and E. G. Paulson Jr. (1980), On the definition of droughts, Water Resour. Res., 16(2), 297-302.

Enfield, D. B., A. M. Mestas-Nuñez, and P. J. Trimble (2001), The Atlantic Multidecadal Oscillation and its relation to rainfall and river flows in the continental United States, Geophys. Res. Lett., 28(10), 2077-2080.

Fritts, H. C. (1991), Reconstructing Large-Scale Climatic Patterns From Tree-Ring Data: A Diagnostic Analysis, 286 pp., Univ. of Ariz. Press, Tucson.

Fye, F. K., D. W. Stahle, and E. R. Cook (2003), Paleoclimatic analogs to twentieth-century moisture regimes across the United States, Bull. Am. Meteorol. Soc., 84, 901-909.

Graumlich, L. J., M. F. J. Pisaric, L. A. Waggoner, J. S. Littell, and J. C. King (2003), Upper Yellowstone River flow and teleconnections with Pacific Basin climate variability during the past three centuries, Clim. Change, 59(1-2), 245-262.

Gray, S. T., J. L. Betancourt, C. L. Fastie, and S. T. Jackson (2003), Patterns and sources of multidecadal oscillations in drought-sensitive tree-ring records from the central and southern Rocky Mountains, Geophys. Res. Lett., 30(6), 1316, doi:10.1029/2002GL016154.

Gray, S. T., L. J. Graumlich, J. L. Betancourt, and G. T. Pederson (2004), A tree-ring based reconstrution of the Atlantic Multidecadal Oscillation since 1567 A.D., Geophys. Res. Lett., 31, L12205, doi:10.1029/ 2004GL019932.

Grissino-Mayer, H. (1996), A 2129-year reconstruction of precipitation for northwestern New Mexico, U.S.A., in Tree-Rings, Environment and Humanity, edited by J. S. Dean, D. M. Meko, and T. W. Swetnam, pp. 191-204, Radiocarbon, Tucson, Ariz.

Hidalgo, H. G., and J. A. Dracup (2003), ENSO and PDO effects on hydroclimatic variations of the upper Colorado River Basin, J. Hydrometeorol., 4, 5-23.

Hidalgo, H. G., and J. A. Dracup (2004), Evidence of the signature of North Pacific multidecadal processes on precipitation and streamflow variations in the upper Colorado River Basin, in The Colorado Plateau: Cultural, Biological, and Physical Research, edited by C. van Riper, III and K. L. Cole, pp. 257-265, Univ. of Ariz. Press, Tucson.

Hidalgo, H. G., T. C. Piechota, and J. Dracup (2000), Alternative principal components regression procedures for dendrohydrologic reconstructions, Water Resour. Res., 36(11), 3241-3249.

Hidalgo, H. G., J. A. Dracup, G. M. MacDonald, and J. K. King (2001), Comparison of tree species sensitivity to high and low extreme hydroclimatic events, Phys. Geogr., 21, 115-134.

Kaplan, A., M. Cane, Y. Kushnir, A. Clement, M. Blumenthal, and B. Rajagopalan (1998), Analyses of global sea surface temperature 18561991, J. Geophys. Res., 103(C9), 18,567-18,589.

Kushnir, Y., Y. Tourre, and B. Rajagopalan (1997), Decadal and multidecadal variability in the Atlantic SST and sea level pressure, paper presented at the Atlantic Climate Variability Meeting, Lamont-Doherty Earth Obs., Columbia Univ., New York, 24-26 Sept.

Mantua, N. J., S. R. Hare, J. M. Wallace, and R. C. Francis (1997), A Pacific interdecadal climate oscillation with impacts on salmon production, Bull. Am. Meteorol. Soc., 78, 1069-1079.

McCabe, G. J., M. A. Palecki, and J. L. Betancourt (2004), Pacific and Atlantic Ocean influences on multidecadal drought frequency in the United States, Proc. Natl. Acad. Sci. U. S. A., 101, 4136-4141.

Meko, D. M., C. W. Stockton, and W. R. Boggess (1995), The tree-ring record of severe sustained drought in the Southwest, Water Resour. Bull., $31,789-801$.

Meko, D. M., M. D. Therrell, C. H. Baisan, and M. K. Hughes (2001), Sacramento River flow reconstructed to A.D. 869 from tree-rings, J. Am. Water Resour. Assoc., 4, 1029-1039.
Minobe, S. (1997), A 50-70 year climatic oscillation over the North Pacific and North America, Geophys. Res. Lett., 24(6), 683-686.

Mitra, S. K., and J. Kaiser (1993), Handbook for Digital Signal Processing, 1312 pp., John Wiley, Hoboken, N. J.

Namias, J. (1983), Some causes of United States drought, J. Clim. Appl. Meteorol., 22, 30-39.

Newman, M., and P. D. Sardeshmukh (1995), A caveat concerning singular value decomposition, J. Clim., 8, 352-360.

Newman, M., G. P. Compo, and M. A. Alexander (2003), ENSO-forced variability of the Pacific Decadal Oscillation, J. Clim., 16, 3853-3857.

Piechota, T. C., F. H. S. Chiew, and J. A. Dracup (2001), Hydrological implications of the El Niño-Southern Oscillation (ENSO): Observations and hydrologic forecasting, in Land Surface Hydrology, Meteorology, and Climate: Observations and Modeling, Water Sci. Appl. Ser., vol. 3, edited by V. Lakshmi, J. Albertson, and J. Schaake, pp. 231-246, AGU, Washington, D. C.

Redmond, K. T., and R. W. Koch (1991), Surface climate and streamflow variability in the western United States and their relationship to largescale circulation indices, Water Resour. Res., 27(9), 2381-2399.

Stahle, D. W., et al. (1998), Experimental dendroclimatic reconstruction of the Southern Oscillation, Bull. Am. Meteorol. Soc., 79, 2137-2152.

Stahle, D. W., E. R. Cook, M. K. Cleaveland, M. D. Therrell, D. M. Meko, H. D. Grissino-Mayer, E. Watson, and B. H. Luckman (2000), Tree-ring data document 16th century megadrought over North America, Eos Trans. $A G U, 81(12), 121,125$.

Stahle, D. W., F. K. Fye, and E. R. Cook (2003), 16th century megadrought: Convergence and propagation of decadal drought modes over North America?, paper presented at the CLIVAR/PAGES/IPCC workshop, A Multi-Millennia Perspective on Drought and Implications for the Future, Tucson, Ariz., 18-21 Nov.

Stockton, C. W., and G. C. Jacoby Jr. (1976), Long-term surface-water supply and streamflow trends in the upper Colorado River Basin based on tree-ring analysis, Lake Powell Res. Project Bull. 18, Inst. of Geophys. and Planet. Phys., Univ. of Calif., Los Angeles.

Thompson, L. G., and E. Mosley-Thompson (1989), One-half millennia of tropical climate variability as recorded in the stratigraphy of the Quelccaya Ice Cap, Peru, in Aspects of Climate Variability in the Pacific and the Western Americas, Geophys. Monogr. Ser., vol. 55, edited by D. H. Peterson, pp. 15-31, AGU, Washington, D. C.

Tourre, Y. M., B. Rajagopalan, and Y. Kushnir (1999), Dominant patterns of climate variability in the Atlantic Ocean during the last 136 years, J. Clim., 12, 2285-2299.

U.S. Bureau of Reclamation (USBR) (1998), Biological assessment project, U.S. Dep. of the Interior, Washington, D. C. (Available at http:// www.usbr.gov/main/index.html.)

U.S. Geological Survey (2004), Streamflow data for the United States, U.S. Dep. of the Interior, Washington, D. C. (Available at http://www.usgs. gov.)

Weakly, H. E. (1965), Recurrence of drought in the Great Plains during the last 700 years, Agric. Eng., 46, 85 .

Woodhouse, C. A., and J. T. Overpeck (1998), 2000 years of drought variability in the central United States, Bull. Am. Meteorol. Soc., 79, 2693-2714.

Zhang, Y., J. M. Wallace, and N. Iwasaka (1996), Is climate variability over the North Pacific a linear response to ENSO?, J. Clim., 9, 1468-1478.

Zhang, Y., J. M. Wallace, and D. S. Battisti (1997), ENSO-like interdecadal variability, J. Clim., 10, 1004-1020.

H. G. Hidalgo, Climate Research Division, Scripps Institution of Oceanography, University of California, San Diego, 9500 Gilman Drive, La Jolla, CA 92093-0224, USA. (hhidalgo@ucsd.edu) 